\title{
Trichostatin A sensitizes cisplatin-resistant A549 cells to apoptosis by up-regulating death-associated protein kinase
}

\author{
Jun $\mathrm{WU}^{1,2}$, Cheng-ping $\mathrm{HU}^{1, *}$, Qi-hua $\mathrm{GU}^{1}$, Ye-peng $\mathrm{LI}^{1}$, Min SONG ${ }^{1}$ \\ ${ }^{1}$ Department of Respiratory Medicine, Xiangya Hospital, Central South University, Changsha 410008, China; ${ }^{2}$ Institute of Respiration, \\ Guangdong Medical College, Zhanjiang 524023, China
}

\begin{abstract}
Aim: To investigate the apoptosis-inducing effect of trichostatin A (TSA) in the human lung adenocarcinoma cisplatin-resistant cell line (A549/CDDP) and to examine whether TSA can enhance sensitivity to cisplatin treatment and the underlying molecular mechanisms of such an enhancement.

Methods: Cell viability was evaluated using the Neutral Red assay. Apoptosis was assessed using Hoechst 33258 staining and flow cytometry analysis. Protein expression was detected by Western blotting. To determine the role of Death-associated protein kinase (DAPK) in TSA-induced apoptosis in the A549/CDDP cell line, cells were transfected with pcDNA3.1(+)-DAPK, which has a higher expression level of DAPK compared to endogenous expression, and DAPK activity was inhibited by both over-expression C-terminal fragment of DAPK which may competitive binding DAPK substrates to inhibit the function of DAPK and RNA interference.

Results: TSA induced apoptosis in both A549 cells and A549/CDDP cells. TSA enhanced the sensitivity of A549/CDDP cells to cisplatin, along with concomitant DAPK up-regulation. When DAPK was over-expressed, A549/CDDP cells became sensitive to cisplatin and the cytotoxicity of TSA could be increased. Moreover, the cytotoxicity of TSA could be alleviated by inhibition of DAPK activity by the expression of a recombinant C-terminal fragment of DAPK or RNA interference.

Conclusion: TSA induced sensitivity to cisplatin treatment in cisplatin-resistant A549 cells. The up-regulation of DAPK is one of the mechanisms mediating sensitization to TSA-induced apoptosis in cisplatin-resistant cells.
\end{abstract}

Keywords: trichostatin A; cisplatin-resistance; lung cancer; death-associated protein kinase

Acta Pharmacologica Sinica (2010) 31: 93-101; doi: 10.1038/aps.2009.183

\section{Introduction}

Lung cancer is one of the most common cancers worldwide. About $80 \%$ of lung cancers are non-small cell lung cancer (NSCLC). Although surgery remains the primary treatment at the early stages of cancer development, chemotherapy has been widely used in combination with surgery to treat lung cancer due to a high rate of tumor recurrence ${ }^{[1]}$. For NSCLC, clinical trial data have demonstrated that cisplatin adjuvant chemotherapy significantly improves patients' survival ${ }^{[1-4]}$. However, the overall 5-year survival rate remains less than $15 \%$, primarily due to resistance to cisplatin in both the primary and recurrent tumors.

The mechanism of cisplatin-resistance has been associated with multiple factors, including changes in DNA repair and cellular accumulation and detoxification of the drug as well

\footnotetext{
* To whom correspondence should be addressed.

E-mail huchengp28@yahoo.com.cn

Received 2009-06-30 Accepted 2009-11-19
}

as inhibition of apoptosis ${ }^{[5]}$. In treating lung cancers, chemosensitivity to cisplatin is affected by changes in gene expression, including genes known to be associated with cell cycle regulation and apoptosis ${ }^{[6,7]}$.

Epigenetic alterations, such as histone acetylation and methylation of gene promoters, contribute to the changes in gene expression. The dys-regulation in epigenetics can affect the onset and progression of cancer ${ }^{[8,9]}$. Histone deacetylase (HDAC) inhibitors have been known to promote transcription of genes required for cell differentiation and apoptosis; therefore, they may also induce differentiation and promote apoptosis in various tumors ${ }^{[10-13]}$.

Trichostatin A (TSA) is one such HDAC inhibitor. It was originally isolated from Streptomyces hygroscopicus and identified as a fungistatic antibiotic that inhibits all class I and II HDACs. TSA can alter the expression of $2 \%-5 \%$ of genes ${ }^{[14]}$ and can act as a chemo-sensitizer in cells of ovarian cancer, gastric cancer, and erythroleukemia ${ }^{[15-17]}$. Although the hyperacetylation of histones following inhibition of HDAC activ- 
ity could contribute to a general increase in gene expression including cell cycle inhibitor gene p21, p53, DAPK and the von Hippel-Lindau tumor suppressor genes as well as the proapoptotic genes Bax and $\mathrm{Bad}^{[18-21]}$, the molecular mechanisms of TSA-sensitized cytotoxicity to chemotherapeutic drugs remain largely unknown.

Death-associated protein kinase (DAPK), a modulator of apoptosis, is a cytoskeleton-localized $\mathrm{Ca}^{2+} /$ calmodulin (CaM)-regulated serine/threonine kinase that modulates cell death ${ }^{[22]}$. Recently, it was demonstrated that impaired translation of DAPK mRNA was involved in the acquisition of cisplatin resistance in human cancer cells ${ }^{[23]}$. However, how it is involved in the development of resistance to chemotherapy in cancer cells is unknown. Based on these observations, we hypothesized that DAPK might play an important role in TSAinduced apoptosis in the cisplatin (CDDP)-resistant A549 lung cancer cell line (A549/CDDP).

In this study, we report that TSA enhances the chemosensitivity of A549/CDDP cells, which correlated with the upregulation of DAPK.

\section{Materials and methods Cell culture}

Cells from the lung cancer cell line A549 and the CDDPresistant derivative A549/CDDP were gifts from Cell Center of Cell Culture (Central South University, Changsha, China). They were cultured in Dulbecco's modified Eagle's medium (DMEM, Gibco BRL, Grand Island, NY, USA) containing 100 $\mu \mathrm{g} / \mathrm{mL}$ penicillin and $100 \mu \mathrm{g} / \mathrm{mL}$ streptomycin and supplemented with $10 \%$ calf blood serum (Sijiqing Laboratories, Hangzhou, China) at $37^{\circ} \mathrm{C}$ in a humidified atmosphere with $5 \% \mathrm{CO}_{2}$. Then $2 \mu \mathrm{mol} / \mathrm{L}$ cisplatin (Qilu Pharmaceutical Co, Ltd, Shandong, China) was added to the medium of the A549/ CDDP cell line. A549/CDDP cells were cultured in complete DMEM medium without cisplatin for $3 \mathrm{~d}$ before being used in experiments.

\section{Plasmids and RNA interference}

The pcDNA3.1(+)-DAPK, pcDNA3.1(+)-DCTP, pcDNA3.1(+) and pDsRed1-N1-U6 shRNA vectors were gifts from Dr Haitao ZHANG (Guangdong Medical College, China).

The synthetic sequences (sense, 5'-CGTAACCTATATCCTCCTAAGTTCAAGAGACTTAGGAGGATATAGGTTATTTTTTGGAAG-3', antisense, 5'-GATCCTTCCAAAAAA TAACCTATATCCTCCTAAGTCTCTTGAACTTAGGAGGATATAGGTTACGGTAC-3') were annealed and cloned into pDsRed1-N1-U6 shRNA vectors.

\section{Cellular transfection}

The cells were transfected with different vectors using Lipofectamine 2000 transfection reagent (Invitrogen) according to the manufacturer's guidelines. Stable cell lines were cultured in medium containing $800 \mu \mathrm{g} / \mathrm{mL}$ G418 (Invitrogen). G418 concentration was reduced to $400 \mu \mathrm{g} / \mathrm{mL}$ after three weeks. Cells were treated with TSA or cisplatin and cell viability was determined by cytotoxicity assay using the Neutral Red assay.

\section{Treatment with cisplatin or TSA}

Both A549/DDP and A549 cells were cultured in 96-well plates $\left(1.0 \times 10^{5}\right.$ cells/well $)$ and treated with different concentrations of cisplatin or TSA (Sigma, St Louis, MO, USA) at $37^{\circ} \mathrm{C}$ in a humidified atmosphere with $5 \% \mathrm{CO}_{2}$ for $24 \mathrm{~h}$.

\section{Combined treatment with cisplatin and TSA}

A549/CDDP cells were cultured in 24 -well plates $\left(3.0 \times 10^{5}\right.$ cells/well) and treated with different concentrations of cisplatin and TSA at $37^{\circ} \mathrm{C}$ in a humidified atmosphere with $5 \% \mathrm{CO}_{2}$ for $24 \mathrm{~h}$. The cells were divided into three groups: the first group was cultured with different concentrations of cisplatin; the second group was cultured with $31.25 \mathrm{nmol} / \mathrm{L}$ TSA and cisplatin; and the third group was cultured with $62.5 \mathrm{nmol} / \mathrm{L}$ TSA and cisplatin.

\section{Cell viability assays}

Following the drug treatments described above, cytotoxicity assays were performed as described previously ${ }^{[24]}$. Briefly, the drug-containing medium from each well was replaced with $100 \mu \mathrm{L}$ medium containing $50 \mathrm{mg} / \mathrm{L}$ Neutral Red for an additional 5-h incubation. Then, the cells were rinsed with PBS three times. A volume of $200 \mu \mathrm{L}$ of $1 \%$ acetic acid/50\% ethanol was added to each well to extract the dye from lysosomes of viable cells. The amount of dye was quantified at $540 \mathrm{~nm}$ using a Varioskan Flash Reader spectrophotometer (THERMO, USA). The inhibitory rate of cell growth was calculated as $\left.\left[1-A_{\text {test group }} / A_{\text {control group }}\right)\right] \times 100 \%$.

\section{Flow cytometry analysis}

The cells were collected by centrifugating at $1000 \mathrm{r} / \mathrm{min}$ for 5 min after treatment, washed twice in PBS and fixed with icecold $70 \%$ ethanol overnight. Prior to flow cytometry analysis, the fixed cells were washed once with PBS and incubated with $100 \mu \mathrm{g} / \mathrm{mL}$ propidium iodide (Sigma, USA) plus $200 \mu \mathrm{g} / \mathrm{mL}$ Rnase (Promega,USA) for $10 \mathrm{~min}$. The DNA profile was analyzed by flow cytometry (EPICS XL, Coulter, Fullerton, CA, USA). The percent of apoptosis is calculated as the percentage of the sub- $\mathrm{G}_{1}$ peak as determined by FACS analysis cell-cycle profile following propidium iodide staining ${ }^{[25]}$.

\section{Hoechst 33258 staining}

Apoptosis was evaluated by in situ uptake of propidium iodide and Hoechst 33258 as described by McKeague et al ${ }^{[26]}$. In brief, after being treated with TSA, the cells were washed with PBS, and incubated in PBS containing $40 \mu \mathrm{g} / \mathrm{mL}$ propidium iodide and $2.5 \mu \mathrm{g} / \mathrm{mL}$ Hoechst 33258 (Sigma, USA) for $10 \mathrm{~min}$. A volume of $500 \mu \mathrm{L}$ of methanol:acetic acid (3:1) fixative was then added directly to each well. Cells were viewed under fluorescence microscopy (Nikon Eclipse ET2000-E, Japan). Four replicate wells were analyzed for each treatment by quantitative and qualitative examination of four random fields in each well. The apoptotic index was calculated from the number of apoptotic nuclei vs total number of nuclei in each 
visual field.

\section{Western blot analysis of DAPK expression}

The cells were collected, washed twice with PBS and incubated with cell decomposition buffer $(\mathrm{pH} 8.0)$ that contained $50 \mathrm{mmol} / \mathrm{L}$ Tris-HCl, $150 \mathrm{mmol} / \mathrm{L} \mathrm{NaCl}, 5 \mathrm{mmol} / \mathrm{L}$ EDTA, $1 \%$ NP40, 0.05\% PMSF, $2 \mu \mathrm{g} / \mathrm{mL}$ aprotinin (Sigma, USA), and $2 \mu \mathrm{g} / \mathrm{mL}$ leupeptin (Sigma, USA). The level of proteins was determined by Western blot with a DAPK monoclonal antibody (clone-55, Sigma, USA), anti-DAPK-phosphoserine308 monoclonal antibody (Sigma, USA), and anti- $\beta$-actin monoclonal antibody (clone AC-74, Sigma, USA). Primary antibodies were detected with goat anti-mouse or goat anti-rabbit antibodies conjugated to horseradish peroxidase using enhanced chemiluminescence (Beyotime Institute of Biotechnology, Jiangsu, China). Photographs were taken with the FluerChem SP8900 automatic photomicrograph system (ALPHA, USA) and analyzed.

\section{Statistical analysis}

Data are presented as mean $\pm S D$ and were analyzed using the Student's $t$-test and Student-Newman-Keuls (SNK) test. $P<0.05$ was considered to be statistically significant.

\section{Results}

\section{Effect of TSA on A549 cells and A549/CDDP cells}

Consistent with our previous reports ${ }^{[27]}$, here we showed that the $\mathrm{IC}_{50}$ of cisplatin to A549 cells and A549/CDDP cells was $2.36 \pm 0.10 \mu \mathrm{mol} / \mathrm{L}$ and $30.27 \pm 1.50 \mu \mathrm{mol} / \mathrm{L}$, respectively (Figure 1A). A549/CDDP cells were 12.8 times more resistant than the parental A549 cells. Western blot analysis showed that A549/ CDDP cells had a lower expression of DAPK than the A549 cell line (Figure 1B).

As shown in Figure 2A, morphological evaluation using Hoechst 33258/PI staining with fluorescence microscopy revealed a significant increase in the number of cells showing nuclear condensation and fragmentation after incubation with TSA for $24 \mathrm{~h}$ in both A549 and A549/CDDP cells.

A significant decrease in cell viability was detected by the Neutral Red assay after cells had been treated with different concentrations of TSA for $24 \mathrm{~h}$. The assay showed that the $\mathrm{IC}_{50}$ of TSA in A549 cells and A549/CDDP cells was 418.66 \pm 25.12 $\mathrm{nmol} / \mathrm{L}$ and $446.59 \pm 27.32 \mathrm{nmol} / \mathrm{L}$, respectively $(P>0.05$, Figure $2 \mathrm{~B})$. Apoptosis was measured as the percentage of sub-G1 DNA content, as well as DNA condensation with Hoechst 33258 staining. The results showed that TSA induced apoptosis in a dose-dependent manner (Figure 3).

\section{TSA enhances the sensitivity of A549/CDDP cells to cisplatin}

Low concentrations of TSA (31.25 nmol/L and $62.5 \mathrm{nmol} / \mathrm{L})$ had little effect on cell viability and apoptosis of A549/CDDP cells. The inhibitory rate of cell growth was $1.08 \%$ and $2.33 \%$, respectively (Figure 4). Thus, these two concentrations of TSA were selected to determine whether TSA could sensitize A549/CDDP cells to cisplatin-induced apoptosis.
A

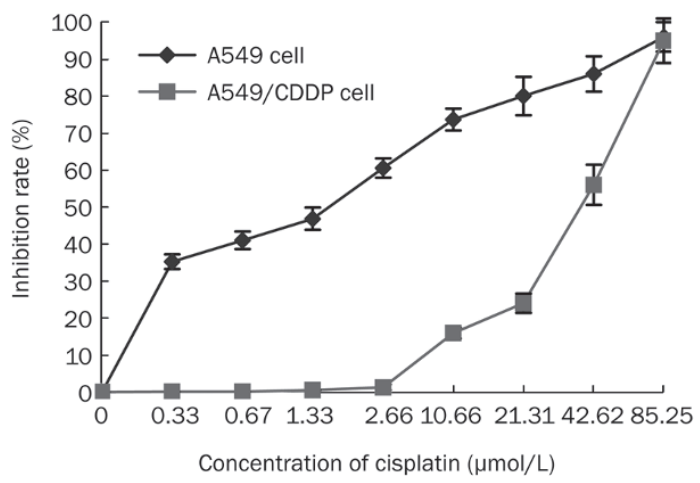

B

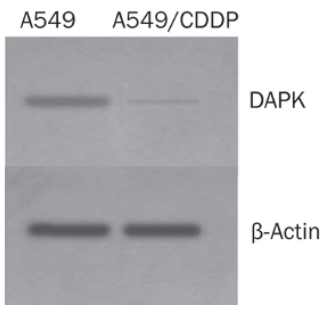

Figure 1. The sensitivity of A549 cells and A549/CDDP cells to cisplatin. (A) The effect of cisplatin on A549 cells and A549/CDDP cells. The plot shows the viability of A549 cells and A549/CDDP cells treated with indicated concentrations of cisplatin. The $\mathrm{IC}_{50}$ of cisplatin to $\mathrm{A} 549$ cells and A549/CDDP cells is $2.36 \pm 0.10 \mu \mathrm{mol} / \mathrm{L}$ and $30.27 \pm 1.50 \mu \mathrm{mol} / \mathrm{L}$, respectively. (B) The expression level of DAPK in A549 cells and A549/ CDDP cells.

The results showed that the $\mathrm{IC}_{50}$ of cisplatin to A549/CDDP cells was at $31.34 \pm 1.23 \mu \mathrm{mol} / \mathrm{L}$ in the absence of TSA, whereas the $\mathrm{IC}_{50}$ was $20.61 \pm 1.80 \mu \mathrm{mol} / \mathrm{L}$ and $18.48 \pm 0.70 \mu \mathrm{mol} / \mathrm{L}$ in the presence of $31.25 \mathrm{nmol} / \mathrm{L}$ and $62.5 \mathrm{nmol} / \mathrm{L}$ TSA, respectively $(P<0.05$ vs control) (Figure 4$)$. The reverse fold was calculated according to the formula $\left(\mathrm{IC}_{50}\right.$ of resisted-drug cell line $) /\left(\mathrm{IC}_{50}\right.$ of combining reversal drug to resistanted-drug cell line).The results showed that the reverse fold was 1.52 and 1.70 in the presence of $31.25 \mathrm{nmol} / \mathrm{L}$ and $62.5 \mathrm{nmol} / \mathrm{L}$ TSA, respectively. This indicates that TSA treatment increases the sensitivity of A549/CDDP cells to cisplatin.

\section{TSA up-regulates DAPK expression in A549/CDDP cells}

The results showed that the expression of DAPK was elevated when A549/CDDP cells were treated with different concentrations of TSA for $24 \mathrm{~h}$ (Figure 5A). In addition, DAPK expression was up-regulated in a time-dependent manner (Figure 5C). The phosphorylation of Serine-308 deactivates DAPK and dephosphorylation relieves auto-inhibition and stimulates the pro-apoptotic activities of DAPK ${ }^{[28,29]}$. Our results showed that the phosphorylation level of DAPK was unchanged or only slightly increased with TSA treatment (Figure 5A, 5C). However, the relative phosphorylation level actually decreased (Figure 5B, 5D). Furthermore, we confirmed that cisplatin had no effect on DAPK expression in A549/CDDP cells (Figure 6). 


\section{A}
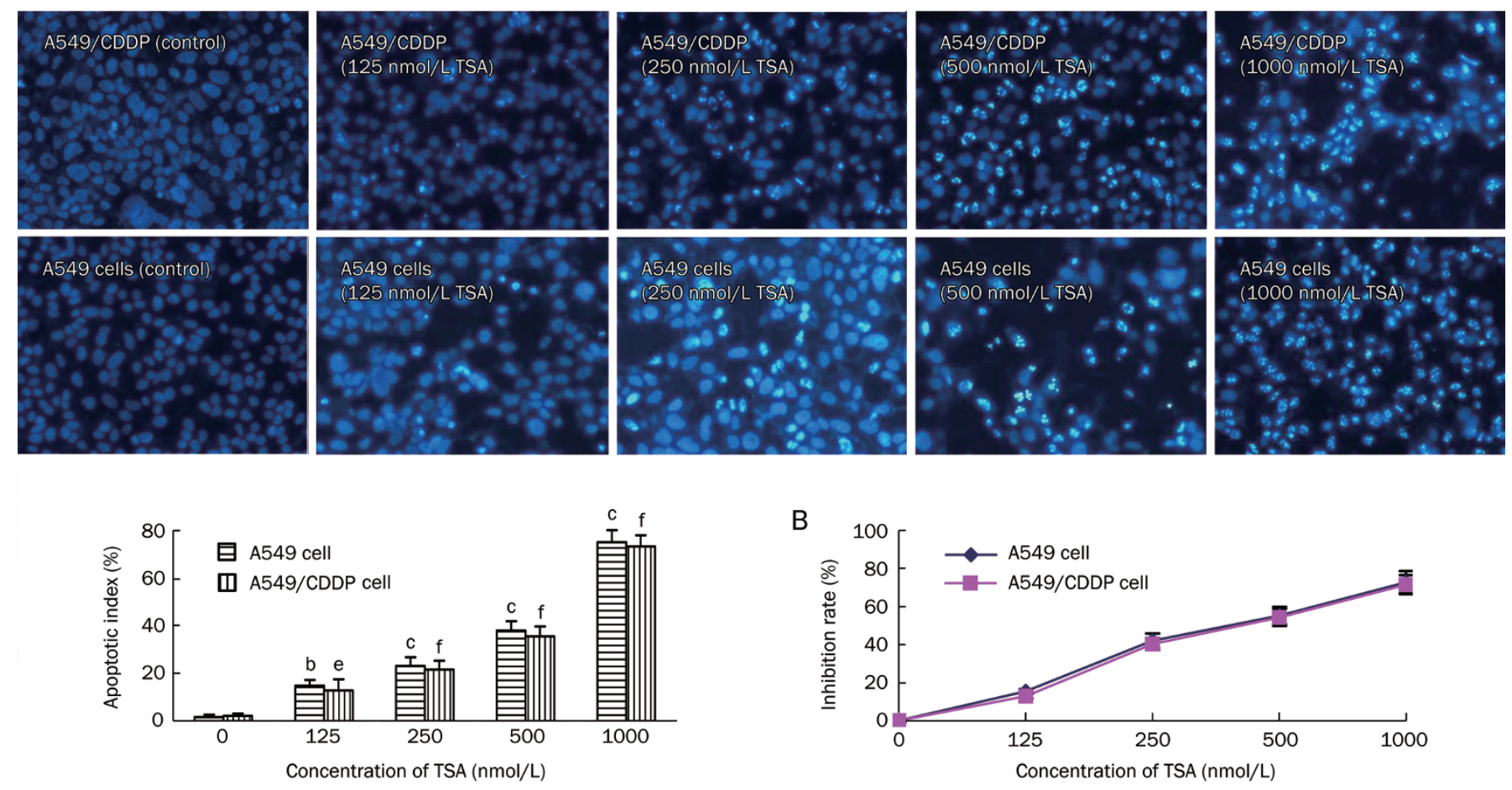

Figure 2. The effect of TSA on A549 cells and A549/CDDP cells. (A) Cells were treated by TSA for $24 \mathrm{~h}$ and stained with Hocest $33258 / \mathrm{PI}$ to measure apoptosis. Apoptotic cells were stained with light-blue and pictures were taken under a $400 \times$ objective. $n=4 . \quad$ Mean \pm SD. ${ }^{b} P<0.05,{ }^{c} P<0.01$ vs A549 control group. ${ }^{e} P<0.05,{ }^{f} P<0.01$ vs A549/CDDP control group. (B) Cell viability is measured by Neutral Red assay after $24 \mathrm{~h}$ TSA treatment at indicated concentrations.

DAPK expression and its activity affect the sensitivity of A549/ CDDP cells to cisplatin

Various expression and interference DAPK vectors were transfected into A549/CDDP cells and the effect of DAPK on the sensitivity of A549/CDDP cells to cisplatin was evaluated. DAPK expression increased in cells transfected by pcDNA3.1(+)-DAPK, whereas there was no significant difference in the DAPK level in cells transfected by pcDNA3.1(+)DCTP or pcDNA3.1(+) as compared to un-transfected cells (Figure 7A). With TSA treatment, DAPK expression increased in cells transfected by pcDNA3.1(+)-DCTP, pcDNA3.1(+), or pcDNA3.1(+)-DAPK (Figure 7B). DCTP, a C-terminal fragment of DAPK, has been reported to mediate inhibition of DAPK activity ${ }^{[30,31]}$.

The results showed that the $\mathrm{IC}_{50}$ of TSA to A549/CDDP cells, transfected by different vectors, was $439.00 \pm 21.16 \mathrm{nmol} / \mathrm{L}$ (pcDNA3.1(+)), 1122.05 $\pm 44.88 \mathrm{nmol} / \mathrm{L}(\mathrm{pcDNA3.1}(+)$-DCTP) and $220.45 \pm 9.927 \mathrm{nmol} / \mathrm{L}(\mathrm{pcDNA} 3.1(+)$-DAPK), whereas the $\mathrm{IC}_{50}$ of TSA to A549/CDDP cells was $418.33 \pm 12.78 \mathrm{nmol} / \mathrm{L}$. These data indicate that over-expression of DAPK increases the cytotoxicity of TSA $(P<0.05$ vs pcDNA3.1(+) control) (Figure $7 \mathrm{C})$. When DAPK was suppressed by DCTP, the cytotoxicity of TSA was inhibited. Furthermore, our data also showed that the $\mathrm{IC}_{50}$ of cisplatin on the transfected A549/CDDP cell was $31.70 \pm 0.93 \mu \mathrm{mol} / \mathrm{L}(\mathrm{pcDNA3} .1(+)), 47.95 \pm 1.06 \mu \mathrm{mol} / \mathrm{L}$ (pcDNA3.1(+)-DCTP) $(P<0.05$ vs control) and $19.05 \pm 0.57$ $\mu \mathrm{mol} / \mathrm{L}$ (pcDNA3.1(+)-DAPK) ( $P<0.05$ vs control) (Figure 7D). These data suggest that DAPK could mediate A549/CDDP cell death induced by cisplatin.

In addition, endogenous DAPK expression was decreased by RNA interference to evaluate the role of DAPK in TSA- or cisplatin-induced A549/CDDP cell death (Figure 8A, 8B). These results show that knock-down of DAPK increases the $\mathrm{IC}_{50}$ of TSA on A549/CDDP cells to $869.08 \pm 34.73 \mathrm{nmol} / \mathrm{L}$, whereas the $\mathrm{IC}_{50}$ of TSA on control A549/CDDP cells was $465.99 \pm 19.57$ $\mathrm{nmol} / \mathrm{L}$ (non-transfected group) and $485.87 \pm 23.16 \mathrm{nmol} / \mathrm{L}$ (control vector group) ( $P<0.05$ vs control) (Figure $8 \mathrm{C})$. Also, the same results were obtained with cisplatin treatment. The results showed that the $\mathrm{IC}_{50}$ of cisplatin on the three groups of A549/CDDP cells was 30.90 $\pm 1.03 \mu \mathrm{mol} / \mathrm{L}$ (non-transfected group), $30.14 \pm 0.87 \mu \mathrm{mol} / \mathrm{L}$ (control vector-transfected group) and $40.63 \pm 1.00 \mu \mathrm{mol} / \mathrm{L}$ (RNA interference vector-transfected group, $P<0.05$ vs control vector-transfected group) (Figure $8 \mathrm{D})$. These results suggest that inhibition of DAPK expression could cause A549/CDDP cell resistance to cisplatin-induced cell death.

\section{Discussion}

Apoptosis is usually deregulated in cancer because of increased expression of anti-apoptotic proteins or decreased expression of pro-apoptotic proteins. In human lung cancers, resistance to drug therapy has been often found to be associ- 

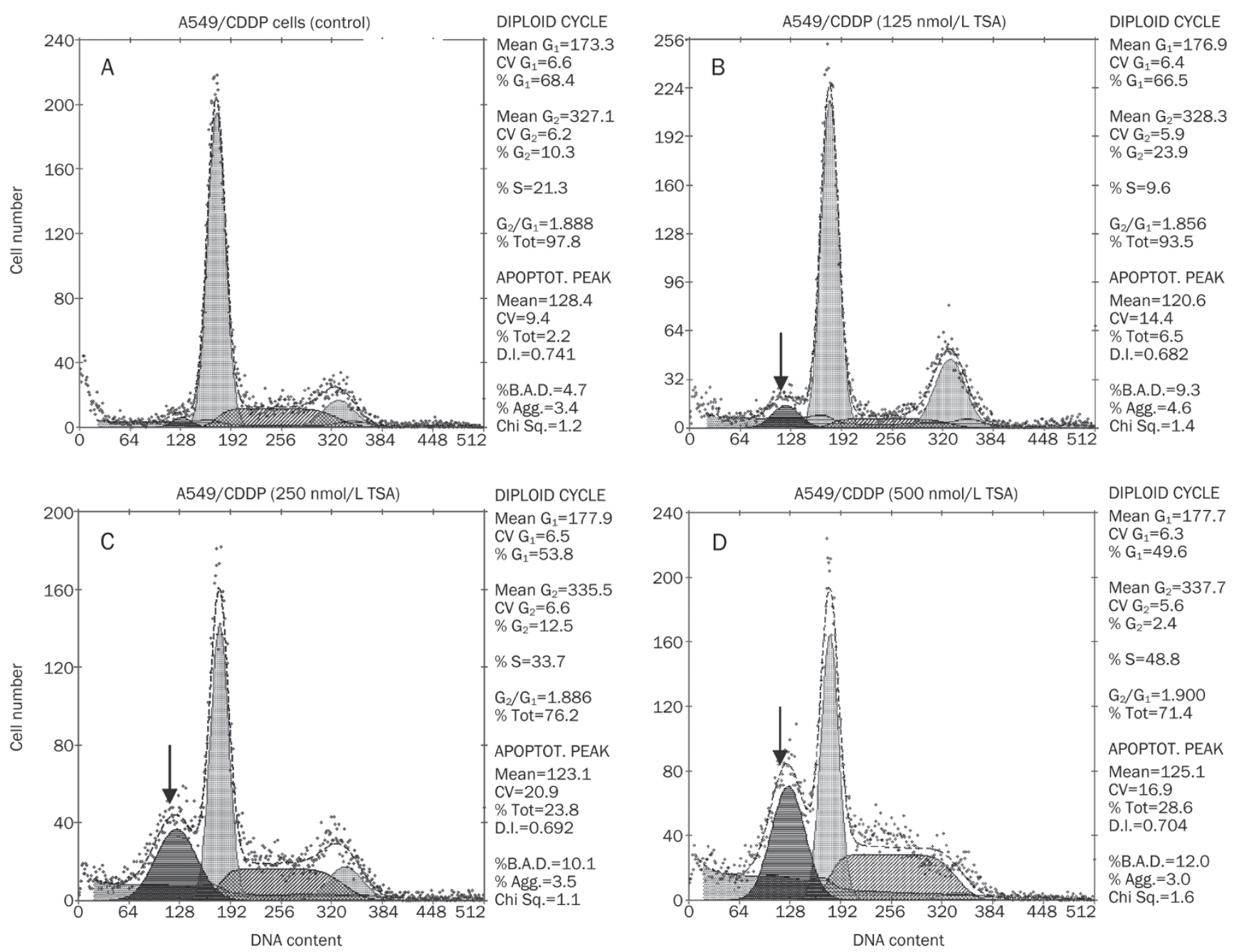

Figure 3. Apoptosis (sub-G $\mathrm{G}_{1}$ ) analyzed by flow cytometry. DNA profile was analyzed by PI staining with flow cytometry. The percent apoptosis is calculated as the percentage sub- $\mathrm{G}_{1}$ peak as determined by cell-cycle analysis (arrow indicated sub- $\mathrm{G}_{1}$ peak).

ated with the silencing of pro-apoptotic proteins including p16INK4a, Bax, and DAPK ${ }^{[32,33]}$. Therefore, the up-regulation of apoptosis-inducing factors might be a promising approach to enhance the efficacy of chemotherapy treatment of multidrug-resistant cancer.

HDAC inhibitors have emerged as a new class of anti-cancer therapeutic agents for both hematologic and solid cancers. More importantly, these inhibitors also display promising anti-tumor activity in clinical trials ${ }^{[3,35]}$. A recent report showed that HDAC inhibitors induced apoptosis in cells of cisplatin-resistant ovarian cancer associated with overexpression of $\mathrm{Bad}^{[36]}$. Moreover, Muscolini et al also reported that an HDAC inhibitor overcome apoptosis resistance to cisplatin by restoring both $\mathrm{p} 73$ and $B a x^{[15]}$. These results demonstrate that HDAC inhibitors overcome resistance to cisplatin by up-regulating the expression of apoptosis-inducing factors. However, less is known about the role of DAPK in the development of chemotherapy resistance in cancers cells, although DAPK has been reported to play an important role in IFN- $\gamma$, tumor necro- sis factor (TNF)- $a$, or Fas-ligand induced apoptosis ${ }^{[37]}$. Previous studies have shown that DAPK was expressed at a basal level in A549 cells ${ }^{[33]}$, but we found that DAPK was downregulated in A549/CDDP cells, suggesting its involvement in the cisplatin resistance of A549/CDDP cells.

In this study, we found that TSA induced dose-dependent apoptosis in both A549 cells and cisplatin-resistant A549/ CDDP cells. We also provide new evidence that A549 cells and cisplatin-resistant A549/CDDP cells undergo similar level of apoptosis with TSA treatment. However, a low concentration of TSA (31.25 nmol/mL) can sensitize A549/CDDP cells to cisplatin-induced cell death. We found that DAPK was up-regulated with TSA treatment in A549/CDDP cells in a dose- and time-dependent manner. DAPK is known to be negatively regulated by auto-phosphorylation of serine-308. The Serine308 phosphorylated DAPK has lower activity than its non-phosphorylated counterpart. The dephosphorylation of serine-308 on DAPK can activate DAPK and induce apoptosis $^{[28,29]}$. Our study demonstrated that the serine-308- 


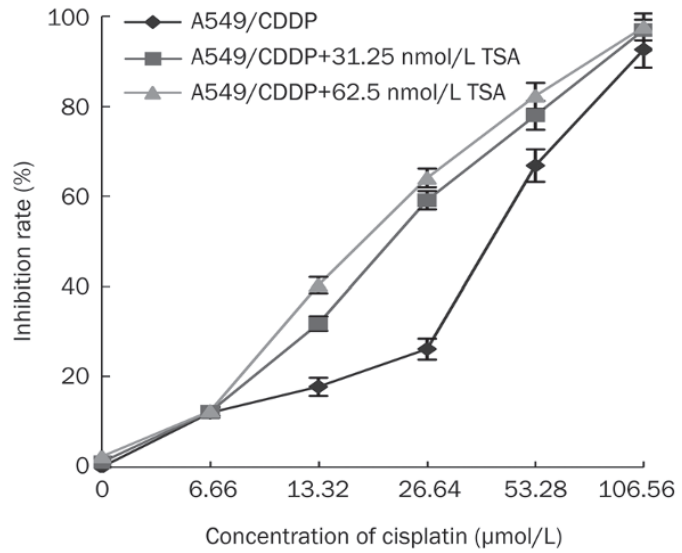

Figure 4. The effect of TSA on the sensitivity of A549/CDDP cells to cisplatin, The $\mathrm{IC}_{50}$ of cisplatin to A549/CDDP cells is at $31.34 \pm 1.23$ $\mu \mathrm{mol} / \mathrm{L}$ in absence of TSA, while the $\mathrm{IC}_{50}$ values are at $20.61 \pm 1.80 \mu \mathrm{mol} / \mathrm{L}$ and $18.48 \pm 0.70 \mu \mathrm{mol} / \mathrm{L}$ in presence of $31.25 \mathrm{nmol} / \mathrm{L}$ and $62.5 \mathrm{nmol} / \mathrm{L}$ TSA, respectively. $n=4$. Mean \pm SD.

phosphorylation level of DAPK remained about the same after TSA treatment (Figure 5B, 5D). This observation suggests that the relative ratio of serine 308 phosphorylated DAPK to the total DAPK decreased with TSA treatment. Therefore, TSA induces elevation of the active form of DAPK, since the level of Serine308 phosphorylated DAPK remained unchanged as compared to the untreated control. However, DAPK expression did not significantly change in A549/CDDP cells treated with cisplatin.

Cell-transfection experiments reconfirmed that increased DAPK expression increased A549/CDDP cells sensitivity to TSA or cisplatin. We also observed that transient DAPK treatment could promote cell apoptosis. To determine whether DAP kinase contributes to cisplatin resistance, we generated a stable-transfection cell line, A549/CDDP/DAPK, which had a higher expression level of DAPK than A549/CDDP cells. Our data showed that stable expression of DAPK in A549/CDDP could sensitize cells to TSA or cisplatin treatment, which is consistent with previous reports that DAPK is a pro-apoptotic factor and may be involved in the mechanisms increasing the chemosensitivity of anticancer drugs of 5-fluorouracil, paclitaxel and TNF-related apoptosis-inducing ligand ${ }^{[16,33]}$. In addition to auto-phosphorylation on Serine-308, the activity of DAPK is also regulated by its C-terminal fragment (DCTP). It has been reported that the expression of DCTP can suppress DAPK activity without affecting the protein level of DAPK. Moreover, DCTP was shown to inhibit PC12 apoptosis induced by DAPK ${ }^{[30]}$. Our results are consistent with these reports in that DCTP did not affect the protein level of DAPK in A549/DCCP cells. Although Raveh et al suggested that the C-terminus of DAPK could block the interaction between DAPK and its substrate and suppress the DAPK activity ${ }^{[31]}$, additional information, such as a structural model, is needed to demonstrate the mechanism. In addition, we also demonstrated that inhibition of DAPK expression causes A549/
A

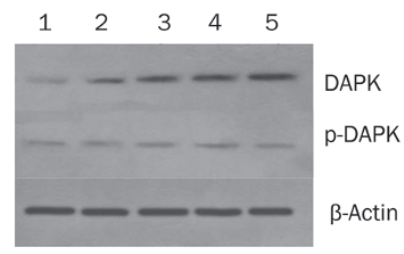

B

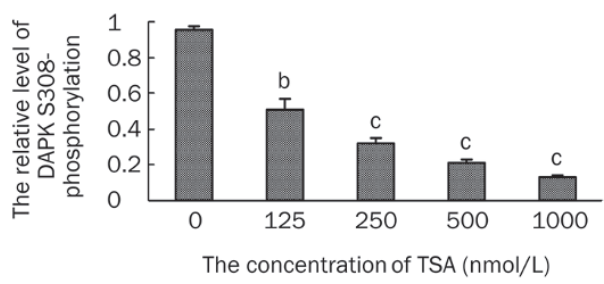

C
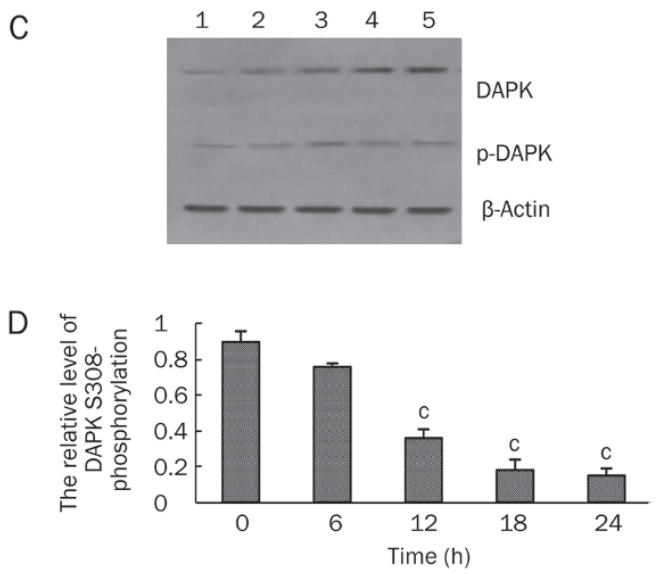

Figure 5. The effect of TSA on DAPK expression and serineS308-phosphorylation level in A549/CDDP cells. (A) Western blot analysis of DAPK expression and serineS308-phosphorylation level induced with indicated concentrations of TSA. 1: control; 2: A549/CDDP cells treated with 125 nmol/L TSA; 3: A549/CDDP cells treated with $250 \mathrm{nmol} / \mathrm{L}$ TSA; 4: A549/ CDDP cells treated with $500 \mathrm{nmol} / \mathrm{L}$ TSA; 5: A549/CDDP cells treated with $1000 \mathrm{nmol} / \mathrm{L}$ TSA. (B) The relative level of DAPK serineS308phosphorylation induced by indicated concentrations TSA was measured by gray scale calculating with AlphaEaseFC software. $n=3$. Mean $\pm S D$. ${ }^{b} P<0.05,{ }^{c} P<0.01$ vs control group. (C) The changes of DAPK expression and serineS308-phosphorylation level induced with $500 \mathrm{nmol} / \mathrm{L}$ TSA for different times were analyzed with Western blot method. 1: control; 2: A549/CDDP cells treated with $500 \mathrm{nmol} / \mathrm{L}$ TSA for $6 \mathrm{~h}$; 3: A549/ CDDP cells treated with $500 \mathrm{nmol} / \mathrm{L}$ TSA for $12 \mathrm{~h}$; 4: A549/CDDP cells treated with $500 \mathrm{nmol} / \mathrm{L}$ TSA for $18 \mathrm{~h}$; 5: A549/CDDP cells treated with $500 \mathrm{nmol} / \mathrm{L}$ TSA for $24 \mathrm{~h}$. (D) The relative of DAPK serineS308phosphorylation level induced with $500 \mathrm{nmol} / \mathrm{L}$ TSA for indicated time periods was measured by gray scale calculating with AlphaEaseFC software. $n=3$. Mean \pm SD. ${ }^{c} P<0.01$ vs control group

CDDP resistance to cisplatin-induced cell death. Thus, DAPK expression might contribute to the increased sensitivity of A549/CDDP cells to cisplatin.

In summary, our present results reveal that treatment with TSA induces apoptosis of A549/CDDP cells and enhances the sensitivity of the cells to cisplatin, possibly mediated by the up-regulation of DAPK. 


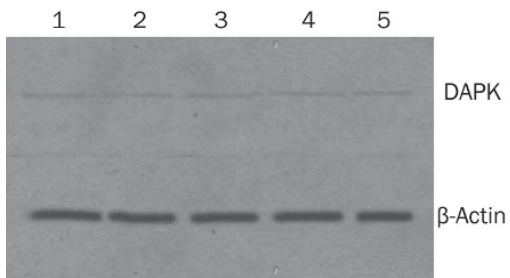

Figure 6. The effect of cisplatin on DAPK expression in A549/CDDP cells. 1: control; 2: A549/CDDP cells treated with $6.66 \mu \mathrm{mol} / \mathrm{L}$ cisplatin; 3: A549/CDDP cells treated with $13.32 \mu \mathrm{mol} / \mathrm{L}$ cisplatin; 4: A549/CDDP cells treated with $26.64 \mu \mathrm{mol} / \mathrm{L}$ cisplatin; 5: A549/CDDP cells treated with $53.28 \mu \mathrm{mol} / \mathrm{L}$ cisplatin.

\section{Acknowledgments}

We thank Dr Hai-tao ZHANG for providing us with the
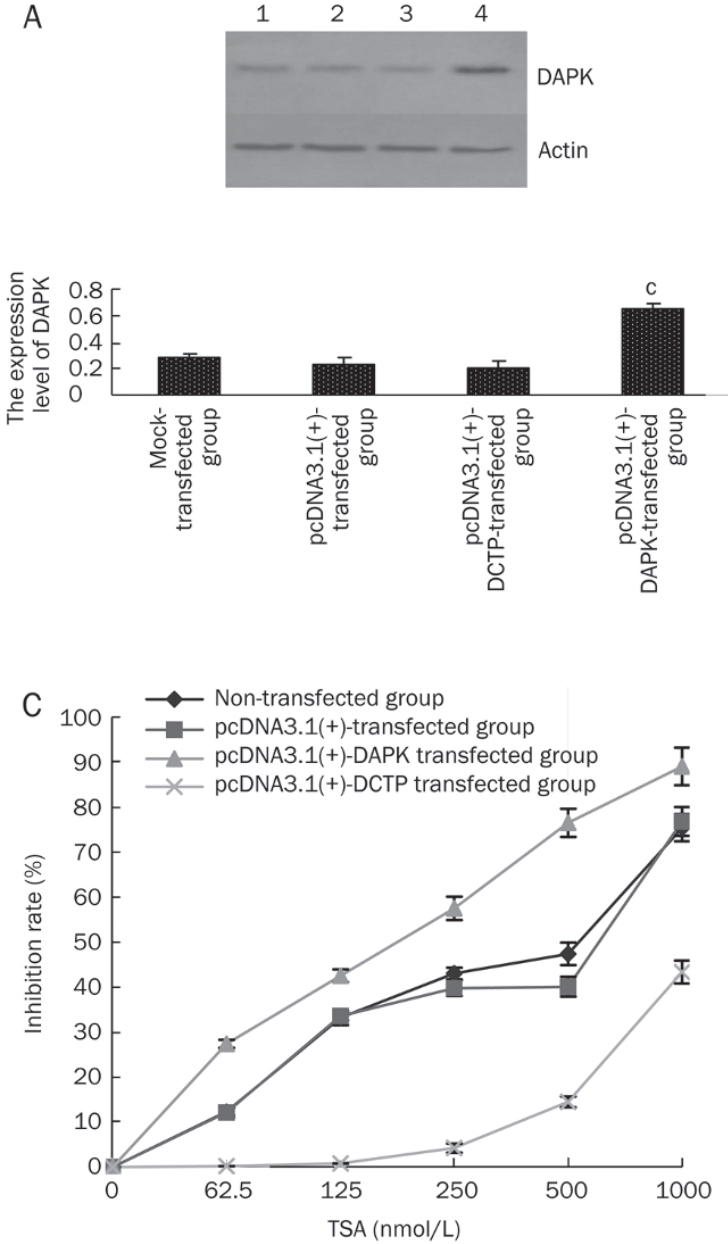

DAPK expression vector.

\section{Author contribution}

Cheng-ping $\mathrm{HU}$ and Jun WU designed research; Jun WU and Min SONG performed research; Qi-hua GU contributed new analytical tools and reagents; Ye-peng LI analyzed data;Cheng-ping HU and Jun WU wrote the paper.

\section{References}

1 Pignon JP, Tribodet H, Scagliotti GV, Douillard JY, Shepherd FA, Stephens RJ, et al. Lung adjuvant cisplatin evaluation: a pooled analysis by the LACE Collaborative Group. J Clin Oncol 2008; 26: 3552-9.

2 Bria E, Cuppone F, Cecere FL, Milella M, Nisticò C, Cognetti F, et al. Adjuvant chemotherapy for non-small cell lung cancer. J Thorac Oncol 2007; 2: S7-11.

3 Winton T, Livingston R, Johnson D, Rigas J, Johnston M, Butts C, et al.
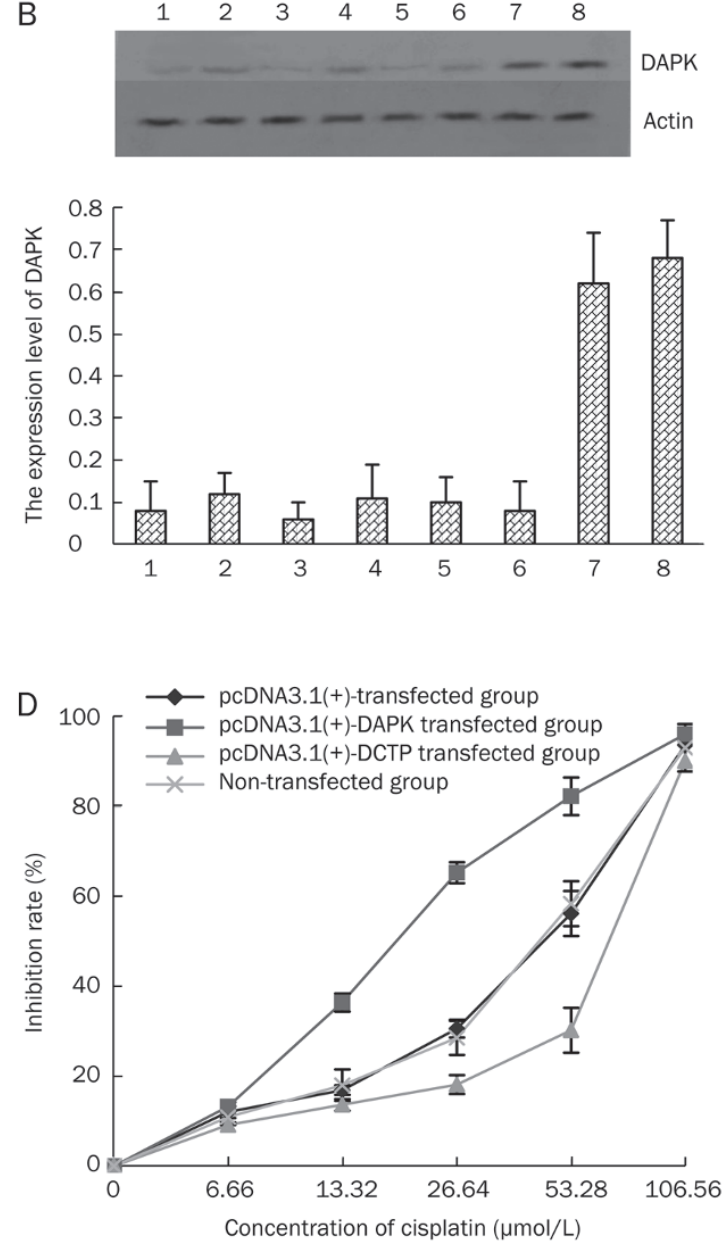

Figure 7. The sensitivity of A549/CDDP cells to TSA and cisplatin is affected by DAPK expression and activity. (A) Western blot analysis of DAPK expression in A549/CDDP cells transfected by various expression vectors. $n=3$. Mean \pm SD. ${ }^{c} P<0.01$ vs control group. 1 : non-transfected group; 2 : pcDNA3.1(+)-tranfected group; 3: pcDNA3.1(+)-DCTP-tranfected group; 4: pcDNA3.1(+)-DAPK-transfected group. (B) Western blot analysis of DAPK expression in TSA-treated A549/CDDP cells transfected by various expression vectors. 1: non-transfected group in absence of TSA; 2: non-transfected group induced by $500 \mathrm{nmol} / \mathrm{L}$ TSA; 3: pcDNA3.1(+)-tranfected group in absence of TSA; 4: pcDNA3.1(+)-tranfected group induced by 500 nmol/L TSA; 5: pcDNA3.1(+)-DCTP-tranfected group in absence of TSA; 6: pcDNA3.1(+)-DCTP-tranfected group induced by 500 nmol/L TSA; 7: pcDNA3.1(+)-DAPKtransfected group in absence of TSA; 8: pcDNA3.1(+)-DAPK-transfected group induced by $500 \mathrm{nmol} / \mathrm{L}$ TSA. (C) The sensitivity of A549/CDDP cells to TSA affected by DAPK expression. $n=4$. Mean \pm SD. (D) The sensitivity of A549/CDDP cells to cisplatin affected by DAPK expression. $n=4$. Mean \pm SD. 
A
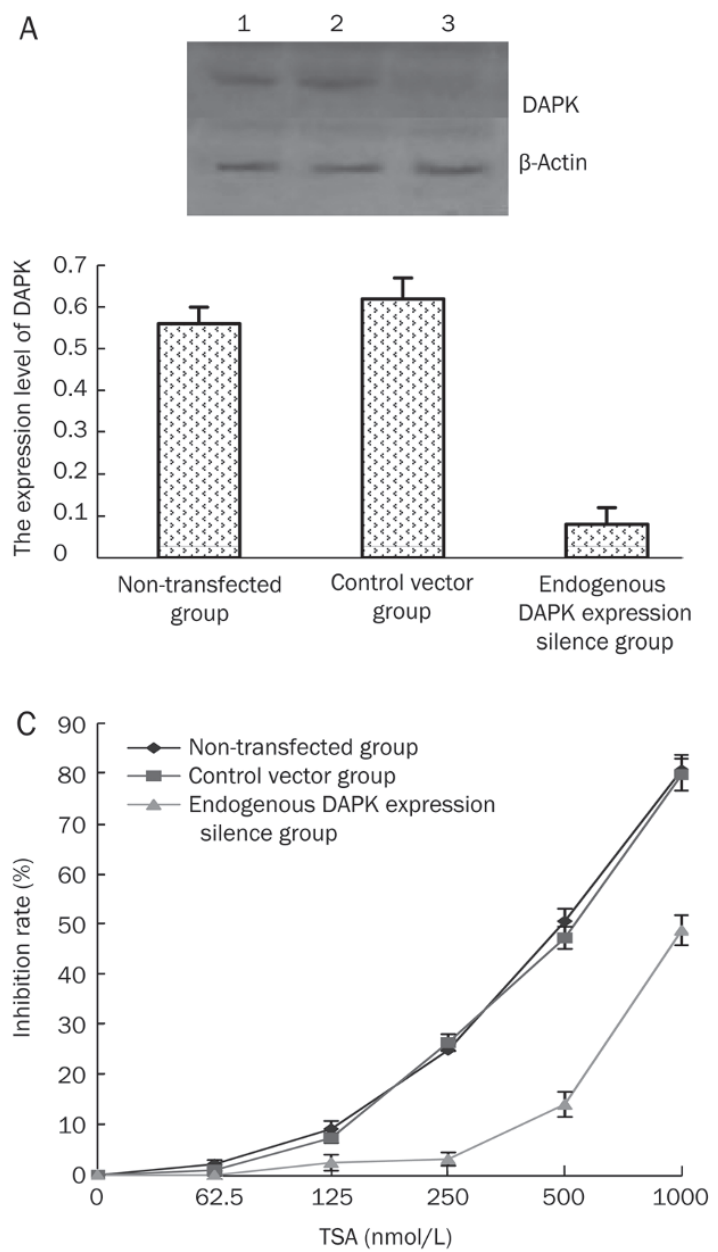

B
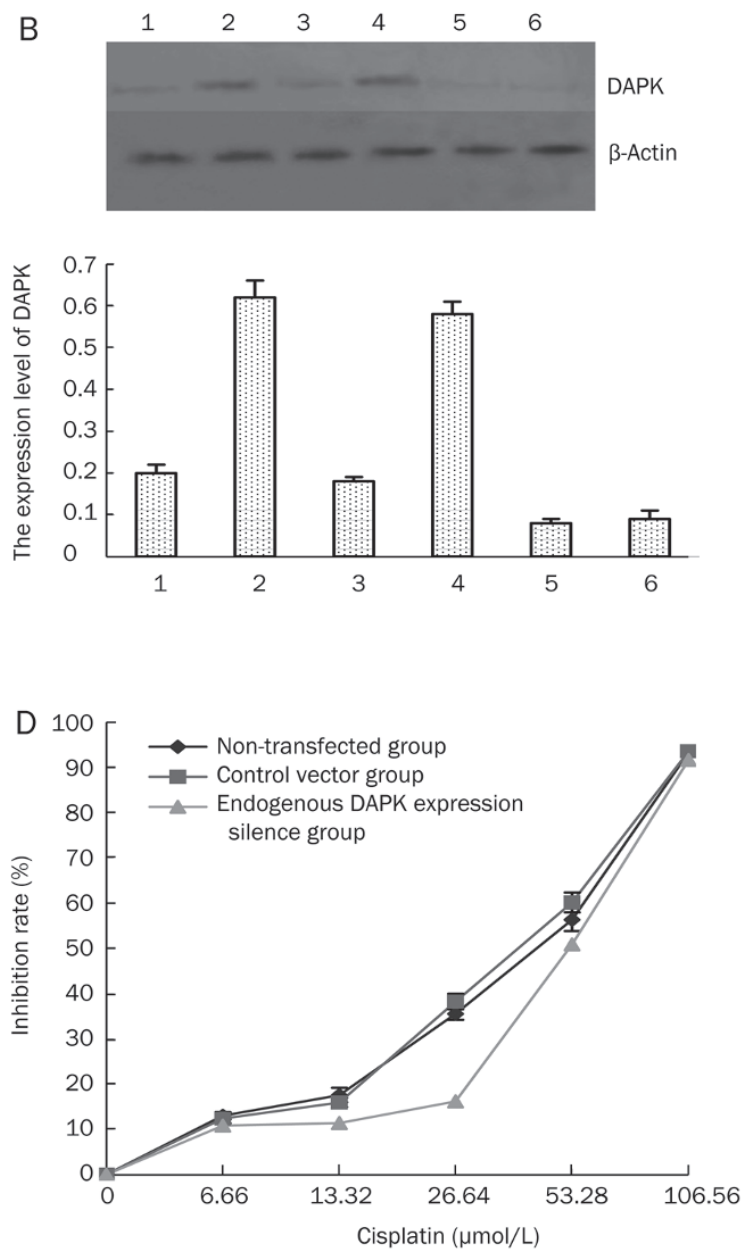

Figure 8. TSA changes the sensitivity of A549/CDDP cells to the cisplatin treatment by affecting DAPK expression. (A) Western blot analysis of DAPK expression in A549/CDDP cells transfected by interference vectors. 1: Non-transfected group 2: control vector group; 3: Endogenous DAPK expression silence group. (B) Western blot analysis of DAPK expression in TSA-treated A549/CDDP cells transfected by interference vectors. 1: nontransfected group in absence of TSA; 2: non-transfected group induced by $500 \mathrm{nmol} / \mathrm{L}$ TSA; 3: Control vector group in absence of TSA; 4: Control vector group induced by $500 \mathrm{nmol} / \mathrm{L} \mathrm{TSA}$; 5: Endogenous DAPK expression silence group in absence of TSA; 6: Endogenous DAPK expression silence group induced by $500 \mathrm{nmol} / \mathrm{L} \mathrm{TSA}$. (C) Effect of endogenous DAPK expression silence on TSA-induced A549/CDDP cells death. $n=4$. Mean $\pm S D$. (D) Effect of endogenous DAPK expression silence on cisplatin-induced A549/CDDP cells death. $n=4$. Mean \pm SD.

Vinorelbine plus cisplatin vs observation in resected non-small-cell lung cancer. N Engl J Med 2005; 352: 2589-97.

4 Douillard JY, Rosell R, De Lena M, Carpagnano F, Ramlau R, GonzálesLarriba JL, et al. Adjuvant vinorelbine plus cisplatin versus observation in patients with completely resected stage IB-IIIA non-small-cell lung cancer (Adjuvant Navelbine International Trialist Association ANITA): a randomised controlled trial. Lancet Oncol 2006; 7: 719-27.

5 Stewart DJ. Mechanisms of resistance to cisplatin and carboplatin. Crit Rev Oncol Hematol 2007; 63: 12-31.

6 Losert D, Pratscher B, Soutschek J, Geick A, Vornlocher HP, Müller $\mathrm{M}$, et al. Bcl-2 downregulation sensitizes non small cell lung cancer cells to cisplatin, but not to docetaxel. Anticancer Drugs 2007; 18 : 755-61.

7 Yang $\mathrm{H}$, Fu JH, Hu Y, Huang WZ, Zheng B, Wang G, et al. Influence of siRNA targeting survivin on chemosensitivity of $\mathrm{H} 460 / \mathrm{cDDP}$ lung cancer cells. J Int Med Res 2008; 36: 734-47.

8 Esteller M. Cancer epigenomics: DNA methylomes and histonemodification maps. Nat Rev Genet 2007; 8: 286-98.
9 Jones PA, Baylin SB. The epigenomics of cancer. Cell 2007; 128: 683-92.

10 Mariadason JM. HDACs and HDAC inhibitors in colon cancer. Epigenetics 2008; 3: 28-37.

11 Kumagai T, Wakimoto N, Yin D, Gery S, Kawamata N, Takai N, et al. Histone deacetylase inhibitor, suberoylanilide hydroxamic acid (Vorinostat, SAHA) profoundly inhibits the growth of human pancreatic cancer cells. Int J Cancer 2007; 121: 656-65.

12 Roy S, Packman K, Jeffrey R, Tenniswood M. Histone deacetylase inhibitors differentially stabilize acetylated p53 and induce cell cycle arrest or apoptosis in prostate cancer cells. Cell Death Differ 2005; 12: 482-91.

13 Habold C, Poehlmann A, Bajbouj K, Hartig R, Korkmaz KS, Roessner $A$, et al. Trichostatin A causes p53 to switch oxidative-damaged colorectal cancer cells from cell cycle arrest into apoptosis. J Cell Mol Med 2008; 12: 607-21.

14 Van Lint C, Emiliani S, Verdin E. The expression of a small fraction of cellular genes is changed in response to histone hyperacetylation. 
Gene Exp 1996; 5: 245-53.

15 Muscolini M, Cianfrocca R, Sajeva A, Mozzetti S, Ferrandina G, Costanzo A, et al. Trichostatin A up-regulates p73 and induces Baxdependent apoptosis in cisplatin-resistant ovarian cancer cells. Mol Cancer Ther 2008; 7: 1410-9.

16 Zhang X, Yashiro M, Ren J, Hirakawa K. Histone deacetylase inhibitor, trichostatin $A$, increases the chemosensitivity of anticancer drugs in gastric cancer cell lines. Oncol Rep 2006; 16: 563-8.

17 Karagiannis TC, Smith AJ, El' Osta A. Radio- and chemo-sensitization of human erythroleukemic K562 cells by the histone deacetylase inhibitor trichostatin A. Hell J Nucl Med 2004; 7: 184-91.

18 Rosato RR, Almenara JA, Grant S. The histone deacetylase inhibitor MS-275 promotes differentiation or apoptosis in human leukemia cells through a process regulated by generation of reactive oxygen species and induction of $p 21^{\text {CIP1/WAF1 }} 1$. Cancer Res 2003; 63: $3637-$ 45.

19 Sawa H, Murakami H, Ohshima Y, Sugino T, Nakajyo T, Kisanuki T, et al. Histone deacetylase inhibitors such as sodium butyrate and trichostatin A induce apoptosis through an increase of the bcl-2related protein Bad. Brain Tumor Pathol 2001; 18: 109-14.

$20 \mathrm{Kim}$ MS, Kwon HJ, Lee YM, Baek JH, Jang JE, Lee SW, et al. Histone deacetylases induce angiogenesis by negative regulation of tumor suppressor genes. Nat Med 2001; 7: 437-43.

21 Zhang HT, Feng ZL, Wu J, Wang YJ, Guo X, Liang NC, et al. Sodium butyrate-induced death-associated protein kinase expression promote Raji cell morphological change and apoptosis by reducing FAK protein levels. Acta Pharmacol Sin 2007; 28: 1783-90.

22 Cohen O, Kimchi A. DAP-kinase: from functional gene cloning to establishment of its role in apoptosis and cancer. Cell Death Differ 2001; 8: 6-15.

23 Bai T, Tanaka T, Yukawa K, Umesaki N. A novel mechanism for acquired cisplatin-resistance: suppressed translation of deathassociated protein kinase mRNA is insensitive to 5-aza-2'-deoxycitidine and trichostatin in cisplatin-resistant cervical squamous cancer cells. Int J Oncol 2006; 28: 497-508.

24 Grare M, Mourer M, Fontanay S, Regnouf-de-Vains JB, Finance C, Duval RE. In vitro activity of para-guanidinoethylcalix4 arene against susceptible and antibiotic-resistant Gram-negative and Gram-positive bacteria. J Antimicrob Chemother 2007; 60: 575-81.

25 Zhang HT, Wu J, Zhang HF, Zhu QF. Efflux of potassium ion is an important reason of $\mathrm{HL}-60$ cells apoptosis induced by Tachyplesin J. Acta Pharmacol Sin 2006; 27: 1367-74.

26 McKeague AL, Wilson DJ, Nelson J. Staurosporine-induced apoptosis and hydrogen peroxide-induced necrosis in two human breast cell lines. Br J Cancer 2003; 88: 125-31.

27 Zhang MC, Hu CP, Chen Q. Effect of down-regulation of survivin gene on apoptosis and cisplatin resistance in cisplatin resistant human lung adenocarcinoma A549/CDDP cells. Zhonghua Zhong Liu Za Zhi 2006; 28: 408-12.

28 Shamloo M, Soriano L, Wieloch T, Nikolich K, Urfer R, Oksenberg D. Death-associated protein kinase is activated by dephosphorylation in response to cerebral ischemia. J Biol Chem 2005; 280: 42290-9.

29 Jin Y, Blue EK, Gallagher PJ. Control of death-associated protein kinase (DAPK) activity by phosphorylation and proteasomal degradation. J Biol Chem 2006; 281: 39033-40.

30 Pelled D, Raveh T, Riebeling C, Fridkin M, Berissi H, Futerman AH, et al. Death-associated protein (dap) kinase plays a central role in ceramide-induced apoptosis in cultured hippocampal neurons. J Biol Chem 2002; 277: 1957-61.

31 Raveh T, Berissi H, Eisenstein M, Spivak T, Kimchi A. A functional genetic screen identifies regions at the $\mathrm{C}$-terminal tail and deathdomain of death-associated protein kinase that are critical for its proapoptotic activity. Proc Natl Acad Sci USA 2000; 97: 1572-7.

32 Gessner C, Liebers U, Kuhn H, StiehI P, Witt C, Schauer J, et al. BAX and $\mathrm{p} 16 \mathrm{INK} 4 \mathrm{~A}$ are independent positive prognostic markers for advanced tumour stage of non small cell lung cancer. Eur Respir J 2002; 19: 134-40.

33 Tang X, Wu W, Sun SY, Wistuba II, Hong WK, Mao L. Hypermethylation of the death-associated protein kinase promoter attenuates the sensitivity to TRAIL-induced apoptosis in human non-small cell lung cancer cells. Mol Cancer Res 2004; 2: 685-91.

34 Shankar S, Srivastava RK. Histone deacetylase inhibitors: mechanisms and clinical significance in cancer: HDAC inhibitorinduced apoptosis. Adv Exp Med Biol 2008; 615: 261-98.

35 Lee MJ, Kim YS, Kummar S, Giaccone G, Trepel JB. Histone deacetylase inhibitors in cancer therapy. Curr Opin Oncol 2008; 20 : 639-49.

36 Strait KA, Warnick CT, Ford CD, Dabbas B, Hammond EH, Ilstrup $\mathrm{SJ}$. Histone deacetylase inhibitors induce $\mathrm{G}_{2}$-checkpoint arrest and apoptosis in cisplatinum-resistant ovarian cancer cells associated with overexpression of the Bcl-2-related protein Bad. Mol Cancer Ther 2005; 4: 603-11.

37 Cohen O, Inbal B, Kissil JL, Raveh T, Berissi H, Spivak-Kroizaman T, et al. DAP-kinase participates in TNF- $\alpha$ - and Fas-induced apoptosis and its function requires the death domain. J Cell Biol 1999; 146: 141-8. 